\title{
RUMOS DA ANTROPOLOGIA NO MUNDO CONTEMPORÂNEO: TENDÊNCIAS METODOLÓGICAS E TEÓRICAS
}

Deise Maia

\section{Na esteira de um debate crítico}

\section{$N$}

este trabalho, aventuro-me a construir algumas notas, seguindo a linha de discussões inspirada nas referências de James Clifford e George Marcus (1991), que assumem, nas interpretações antropológicas, serem o poético e o político dimensões inseparáveis, estando o científico implícito em suas margens. E na trilha dos debates pós-modernos da antropologia americana, procuro lançar inquietações desafiadoras aos cânones mais rígidos da academia, repensando o background metodológico e teórico que fundamentou a produção do conhecimento antropológico. Ao mesmo tempo, busco contextualizar as condições de produção deste conhecimento, vislumbrando o fazer antropológico frente às transformações do mundo contemporâneo, no que diz respeito ao trabalho de campo e às representações etnográficas.

Trata-se de um exercício de reflexão sobre as tendências metodológicas e teóricas que marcam a antropologia no final do século, através da crítica americana que, no conjunto de suas experiências renovadoras, vem-se caracterizando como uma "certa antropologia", provocando um "barulho" e despertando para as novas formas de articular a "experiência". São críticas aos clássicos modelos de representação cultural da antropologia, a partir dos anos 20 - o modernismo em antropologia.

De um lado, apresenta-se um caminho aberto por Clifford Geertz, nos anos 70, que, através de uma abordagem interpretativa, olha a cultura como um conjunto de textos a serem interpretados. A interpretação, 
baseada num modelo de leitura contextual, surgiu como uma alternativa às afirmações de autoridade experiencial. A antropologia interpretativa desmistifica o que anteriormente passara sem questionamento na construção de narrativas, tipos, observações e descrições etnográficas. Contribuiu para uma crescente visibilidade dos processos criativos (poéticos) pelos quais objetos culturais são inventados e tratados como significativos. A concepção das culturas como texto e a análise antropológica como interpretação, sempre provisória, permitiram o estranhamento da autoridade etnográfica. O rompimento com o modelo clássico, porém, é parcial, já que a antropologia de Geertz questiona o processo da produção interpretativa, mas não rompe com a separação radical entre observador e observado e suas culturas. A interpretação está voltada para uma outra cultura separada do antropólogo (Clifford, 1998).

De outro lado, emerge, nos anos 80 , um quadro de perspectivas pós-modernas, tomando o texto etnográfico como objeto de interpretação. É uma discussão que está centrada tanto na forma de pesquisa, quanto na forma de seu texto. Tem a proposta da escrita de textos polifônicos, diálógicos ou testemunhais. É uma linha do debate recente que faz críticas ao positivismo científico, às diversas formas de reducionismo e ao empirismo ingênuo, insinuando ao fazer antropológico uma postura humanista e o caráter sempre provisório e parcial de toda a análise cultural (Trajano Filho, 1988). Através de uma noção retrabalhada de texto, a partir da elaboração da visão de cultura como texto, na perspectiva de Geertz, é que temas como autoridade científica e etnográfica, a crise da representação, recursos teóricos e fazer etnográfico, diálogo e polifonia, poder e dominação são tratados de maneiras diversas, em diferentes "dialetos", com vozes, estilos e interpretações idiossincráticas. Em outros termos, algumas posições são mais moderadas e preocupamse com a procura da "verdade etnográfica"; outras, mais radicais, questionam a possibilidade de qualquer tipo de "objetividade" no contato intersubjetivo.Certas tendências enfatizam o potencial crítico de uma abordagem mais dialógica e polissêmica que descentraliza a autoridade do autor e deixa falar a voz do outro. Há aquelas que exigem do antropólogo, enquanto autor, a responsabilidade sobre a sua voz, seu texto, relevando a consciência da historicidade e contextualidade de seu ponto de vista, tornando a sua interpretação parcial (Lagrou, 1994). Em que pesem as 
particularidades dos trabalhos, são preocupações de: James Clifford, Geòrge Marcus, Meiry Louise Pratt, Vincent Crapanzano, Renato Rosaldo, Stephen Tyler, Talal Assad, Michel Fischer, Paul Rabinow, Marcus Cushman, Roth, Michael Taussig, dentre outros.

Embora algumas experiências venham apresentando a proposição de alternativas textuais e de modos diversos, o enfrentamento de problemas políticos e de crítica cultural, a exemplo de: First-Time de Richard Price (1983); Waiting de Vincent Crapanzano (1985) e Schamanism, Colonialism and Wild Man de Michael Taussing (1987), o pós - modernismo americano tem expressão em relação ao trabalho de desconstrução de textos etnográficos clássicos e não no tocante à produção de etnografias reveladoras das recentes discussões e cânones das novas proposições (Caldeira, 1988).

A reflexão proposta coloca-nos diante da problemática emergente da contemporaneidade, a exemplo dos processos de mundialização econômica e da cultura, assim como, um dos seus corolários, a reposição das diferenças. Ao analisar as realidades contemporâneas, os problemas que a antropologia pretende resolver impõem um constante repensar do seu papel político e social - de uma ciência voltada à crítica cultural - às formas pelas quais tem produzido e representado os significados da cultura.

Para as novas propostas do fazer antropológico, os pósmodernos americanos fazem do texto etnográfico o seu objeto de estudo, recuperando as formas de pesquisa e de seus textos, desde Malinowski até os anos 80. Neste sentido, é importante fazer algumas observações à antropologia que produziu estes textos.

\section{As peculiaridades do fazer antropológico: o modernismo em antropologia}

Enquanto a formação do conhecimento nas diferentes áreas do saber e, também, nas ciências sociais exprime-se na busca do analista e pesquisador em ausentar-se o máximo possível da análise e da exposição de dados, assegurando uma posição de "neutralidade e objetividade" legitimadora da cientificidade, a antropologia tem a sua especificidade. O conhecimento antropológico fundamentou-se na presença do 
pesquisador quer no trabalho de campo, quer no texto etnográfico. $\mathrm{O}$ antropólogo nunca se afastou de seu texto e da exposição de seus dados. Caracterizou-se antes como produtor deste instrumento privilegiado de pesquisa. Em outros termos, de modo objetivo, sua pretensão é ser o mediador entre dois universos culturais, tornando legível para um deles uma outra forma de viver que só o antropólogo vivenciou e traduz, conhece. Como argumenta Caldeira (1988) a presença do antropólogo nos textos é ambígua, já que, ao mesmo tempo, ele se mostra, ao revelar a realidade conhecida, e se retira para garantir a objetividade. Nestes termos, seguindo as pistas de Geertz, descobrimos que a presença do autor nos discursos científicos deve ser compreendida, através de "peculiaridades de uma curiosa estratégia de construção textual". Construção esta que se expressa em diferentes formas conforme, a discursividade introduzida por Malinowski, EvansPrichard, Lévi-Strauss, entre outros (Geertz,1989, p. 94 ).

Malinowski legitimou a figura do antropólogo profissional, através de uma nova abordagem metodológica - observação participante - , o que permitiu uma identidade à antropologia como ciência, provocando uma ruptura metodológica nos procedimentos do pensamento do século XIX, o paradigma representado pelo evolucionismo.O antropólogo deste período, através do trabalho de gabinete, colecionava milhares de fatos etnográficos de todo o mundo, construindo a história da humanidade vista pelo prisma dos deuses, dos sacrifícios, das magias e da religião (Da Matta, 1984). Para esta antropologia não há a legitimação do pesquisador de campo nos moldes malinowskianos. Em termos gerais, prevaleceu um outro modelo de conhecimento etnográfico, uma compilação de folclore, costumes, elaborada por um longo período de convivência, como a de missionários, viajantes, administradores coloniais, alguns dos quais possuíam melhores contatos e mais habilidade na língua nativa do que o "etnógrafo". O etnógrafo e o antropólogo, aquele que descrevia e traduzia os costumes e aquele que era o construtor das teorias gerais sobre a humanidade, eram personagens distintas (Clifford, 1998). No processo de classificação dos costumes "primitivos" separava-se os fatos do contexto de origem, trazendo-os para o universo do antropólogo e de seus leitores. Comparava-se costume com costume. Os "outros" estavam apenas em estágios diferentes de evolução do "eu”. 
A etnografia clássica exprime-se pela experiência pessoal de uma cultura. Com o pesquisador de campo profissional emergiu uma nova fusão de teoria geral com a pesquisa empírica, de análise cultural com descrição etnográfica. $\mathrm{O}$ exercício tradicional da disciplina consistia em desvendar as lógicas de sistemas os mais exóticos e de formações culturais as mais diversas, "uma viagem paradigmática em direção ao paradigma longínquo" (Geertz, 1989, p. 85). Criou-se um novo contexto para falar das diferenças e, ao propor que as culturas fossem entendidas em seus próprios termos, descobrindo o familiar no exótico, a antropologia criticou o etnocentrismo e o racismo. Após conviver algum tempo com um grupo (observação participante), emergir no seu cotidiano, passar por um processo de transformação e "tornar-se nativo", o antropólogo escrevia textos, legitimando suas proposições pelo princípio "estive lá" , o que lhe conferia o poder de falar sobre "o outro". Reconstruía a cultura nativa enquanto totalidade, o que se assentava no postulado de um modelo integrado de cultura. Sustentado por essa aparente unidade do objeto antropológico, o pesquisador supunha poder identificar-se com ele e compreendê-lo totalmente, sem intermediários (Montero, 1991). No texto, aparecia como porta voz dos grupos estudados, afirmando como viviam e como pensavam os diferentes povos. As relações interpessoais davam lugar ao nativo generalizado. Esse novo contexto para a explicação das diferenças era o "relativismo cultural", que sustentava a unidade de cada cultura e, ao mesmo tempo, acentuava a distância entre elas, dificultando que uma cultura falasse da outra em termos críticos - embora a crítica cultural tenha sido o pressuposto em que se ancorou.

No texto clássico, que marcou a etnografia moderna, Os Argonautas do Pacífico Ocidental, Malinowski argumenta sobre a imensa distância entre a apresentação final dos resultados da pesquisa e o material bruto das informações coletadas pelo pesquisador, através de suas próprias observações das asserções dos nativos, do caleidoscópio da vida tribal (Malinowski, 1978). Nesse sentido, há uma transformação do antropólogo para entrar em outra cultura, a necessidade de "aprender a comportar-se como eles", desenvolvendo o sentimento de "empatia". De outro modo, o antropólogo deveria reinterpretar os "dados brutos", dependendo da inspiração oferecida pelos estudos teóricos, por uma 
teoria da cultura. Malinowski estava muito preocupado com o problema retórico de convencer seus leitores de que os fatos, que estava colocando diante deles, eram objetivamente adquiridos e não subjetivamente. Os artifícios literários de Os Argonautas, com suas construções narrativas envolventes, o uso da voz nativa no "presente etnográfico", as dramatizações encenadas, a participação do autor em cenas da vida cotidiana trobriandesa, são técnicas que o autor usou para que tanto sua própria experiência, quanto a experiência dos nativos pudessem também se tornar a experiência do leitor (Stocking, 1983).

A produção do conhecimento antropológico fez-se através do estudo dos povos coloniais numa perspectiva "interstícia - o olhar desde dentro". O enfoque do tipo "colocá-lo todo dentro" para a etnografia e "deixá-lo todo fora para prosa" marcou a forma da passagem do campo para o tex to etnográfico deste primeiro momento (Geertz, 1989, p. 94 -95). O antropólogo descrevia textos etnográficos para os membros de sua própria sociedade e não colocava em questão o caráter de poder que se estabelecia entre as duas sociedades. O princípio "eu estive lá" e, assim, "posso falar do outro" demonstra que a experiência tem servido como eficaz garantia de autoridade etnográfica. Deste modo, evoca tanto uma presença participativa, uma concretude de percepção, uma relação de afinidade emocional, como sugere um conhecimento cumulativo (sobre uma realidade). E esse mundo "o meu povo", concebido como criação da experiência, é subjetivo e não dialógico (Clifford, 1998).

\section{A arte de ourives: questões para a Antropologia na contemporaneidade}

O processo de descolonização dos impérios coloniais, a mundialização da cultura e da economia, o interesse pela própria sociedade (o estudo de grupos urbanos, bairros da periferia, grupos da religião afro-brasileira, entre outros) alteram as condições de produção do conhecimento. $O$ antropólogo não se encontra mais numa situação de exclusividade quanto à produção do conhecimento em relação ao outro. Perdendo o lugar de sujeito absoluto do conhecimento, ele "agora se depara com objetos falantes, com um ponto de vista próprio", que 
aceitam ou se contrapõem às interpretações etnológicas, assumem, recúsam ou corrigem as imagens de si que dividem os acadêmicos em torno na natureza da explicação antropológica (Montero, 1991, p.104).

Ao fazerem uma discussão sobre o momento presente e a reavaliação das idéias dominantes e dos quadros referenciais que orientam os esforços da pesquisa empírica nas ciências humanas, Marcus e Fischer (1986) tratam da crise da representação e referem-se à antropologia utilizando a metáfora da "visão do mundo de ourives", uma vez que a disciplina concentrou sua atenção na interpretação e descrição de processos e culturas "observados de perto". Embora percebida como ciência dedicada ao estudo de sociedades primitivas, isoladas, vem, há algum tempo, aplicando seu "método de ourives" às sociedades complexas de nação-estado e inclusive à própria sociedade do investigador. As inovações contemporâneas no texto etnográfico são reveladoras da direção da antropologia a uma sensibilidade histórica e política de um constante refinamento, que está transformando a maneira como a diversidade cultural é retratada. As mudanças atuais, das convenções do passado, na passagem para o texto sobre outras culturas, constituem o "locus de operação" para a função estratégica contemporânea da antropologia. As regras definidoras da relação autor, objeto, leitor, que permitem a produção, a legibilidade e a legitimidade do texto etnográfico, estão tomando um rumo diverso, em função do processo de autocrítica pelo qual passa a antropologia, na medida em que os mais variados aspectos de sua prática vêm sendo questionados e desconstruídos (Caldeira, 1988).

As experiências vivenciadas colocam, lado a lado, antropólogo e nativo e, ao mesmo tempo, são reveladoras da "diversidade irredutível". Ao contrário dos parâmetros da antropologia moderna, que reconstruía uma totalidade para dar sentido à diversidade, o que se pretende é o ponto de vista do nativo e a diversidade de experiências, cabendo ao antropólogo representar esta diversidade na forma textual. A antropologia norte-americana chama a atenção para o autoritarismo dos modelos tradicionais, insinuando a superação das etnografias monológicas por um dialogismo inspirado em Mikhail Bakhin, em que intersubjetividade e o entrecruzamento de muitas vozes - polifonia têm expressividade (Bakhtin, 1981, Apud. Clifford \& Marcus, 1991). 
Nesse sentido, modos de vida trocam influências, imitam-se entre si, pretendem dominar-se uns aos outros, pretendem traduzir-se reciprocamente, subverter-se entre si. A análise cultural se acha imersa em todo movimento de contestação ao poder.

Apesar das insistentes discussões sobre a incorporação do ponto de vista nativo, hoje, a antropologia vem- se mostrando mais sensível ao reconhecimento da dificuldade desta incorporação. Deste modo, o que se evidencia é a presença autoritária do antropólogo pesquisador quer no ato de pesquisa, quer na interpretação de dados. $\mathrm{O}$ argumento é o caráter ocidental da Antropologia Social e Cultural, implícito em sua matriz disciplinar, que compromete o antropólogo com uma subcultura específica, profissional, formadora de um "olhar" comprometido com uma lógica etnocêntrica, cuja arrogância é sequer percebida pelo pesquisador, a despeito de seus esforços para lograr a neutralidade. Nesses termos, para evitar tal arrogância é necessária uma compreensão da investigação antropológica como uma "etno-lógica", entre outras. O exercício da lógica do antropólogo precisa ser confrontado com o exercício da lógica do nativo, no encontro etnológico (Oliveira, 1990). Sem privilegiar a lógica do pesquisador, há que se dar espaço para a lógica do pesquisado, estabelecendo relações dialógicas simétricas. Apesar do descompasso entre os mundos de interação, a busca da democratização dessas relações constitui-se como imperativo da investigação. É a efetivação de uma "antropologia plurivocal ou polifônica", onde a voz do outro está junto com a do antropólogo. Aqui emerge a questão ética, já que serão constantemente buscadas pré-condições para este tipo de antropologia. Estas pré-condições permitem a "comunidade de argumentação constituída no encontro etnográfico". O diálogo se apresenta como uma modalidade de acordo entre interlocutores numa relação dialógica. Tal dinâmica pode ser observada no trabalho dos pós-modernos, a exemplo de Crapanzano, em seu livro Tuhami, que se revela como um autor envolvido na tensão intelectual e política (Crapanzano, 1980).

A questão da ética universal se faz urgente em uma nova era, isto é, em uma civilização unificada em nível planetário pelas consequiências tecnológicas da ciência. E se a tarefa é fundamentalmente ética, racionalmente universal, para o cientista social a questão é como agir eticamente. No tocante a função da ciência no mundo contemporâneo, 
Oliveira (1990) incorpora, em suas argumentações, debates científicos a respeito das conseqüências reais das ações humanas, sustentando três espaços: o da "micro-esfera" (das normas morais que se concentram na esfera interna - espaço da família, vizinhança); o da "meso-esfera" ( da política nacional ); o da "macro - esfera" (dos interesses vitais de toda a humanidade). Embora estas esferas se articulem, é na "micro" e na "mesoesfera" que a postura relativista dos antropólogos mais se acentua e ganha consistência teórica na lógica da disciplina. A expansão dos processós de globalização carrega em seu bojo uma ameaça constante a esses princípios particularistas (ameaça às minorias), sem levar em conta as tradições morais e culturais de cada grupo.

Saber, ética e ação social supõem a necessidade de um acordo produzido por uma "comunidade de argumentação". Nesse sentido, populações afetadas por programas de desenvolvimento estão cada vez mais conscientes dos efeitos lesivos aos seus interesses e direitos. O conceito de etno-desenvolvimento sugere a idéia de grupos e indivíduos portadores de culturas diferentes e inseridos em situação intercultural (Stavenhagem, 1985, Apud. Oliveira,1990). A ética política consiste na criação de espaços de liberdade, implicando em democratização do Estado, através de programas alternativos. Nesses termos, é preciso que no espaço da "meso-esfera" se articulem ou se compatibilizem os valores particularistas das etnias e das comunidades locais da "micro-esfera" com valores universalistas da "macro".

A crítica pós-moderna aos paradigmas da antropologia, apesar de sua promessa não cumprida - em relação à crítica cultural e a evidência na desconstrução e não na produção de textos - tem sido motivo de calorosas discussões na academia. Com isso, os estudos contemporâneos não deixam de voltar a atenção aos recentes debates, seja para incorporar as novas tendências da pesquisa de campo e da produção de textos, seja para criticar, colocando limites, a uma "ousadia" que incomoda. A tribo acadêmica está em pé de guerra, uma vez que "o campo científico é o espaço de jogo de uma luta concorrencial " (Bourdieu, 1980).

O trabalho de campo, iniciado com Malinowski e seguido por outros antropólogos, ilumina as etnografias na contemporaneidade. Iniciados na antropologia aprendemos a evocar o Pacífico Ocidental e a compreendermos como se fez "etnografia moderna" com nativos de 
"carne e osso.", bem como o perfil da relação observador-observado. Também procuramos perceber a Oceania no recorte de nosso estudo. Entretanto, a aventura a esta nova Oceania coloca outras questões para o "navegador" dessas ilhas do mundo contemporâneo, que acaba por reinventar a prática etnográfica. É a partir dos anos 70 que antropólogos de "antropologias nativas" começaram a se preocupar com o estudo das cidades, das práticas culturais de diferentes grupos, anunciando uma "nova antropologia", que se propõe agora em converter o "familiar" em exótico e a se deparar com um outro pesquisado, aquele que reivindica um diálogo e discute sobre as interpretações antropológicas.

Se, para realizar uma pesquisa, o antropólogo está preso a uma rede de relações com significados específicos, sua inserção em um campo de pesquisa supõe a compreensão de uma outra teia de relações e a negociação de sua presença. $O$ desenvolvimento de um trabalho científico implica em aceitação dos modelos científicos e o reconhecimento pela academia. É preciso incorporar linhas de pesquisa, discussões teóricas e metodológicas dos centros de estudos que estamos envolvidos. Nossos trabalhos serão discutidos com outros cientistas dentro de cânones específicos. É "a ordem do campo científico". Entretanto, os objetos de estudo impõem seus padrões, principalmente se estivermos falando de grupos pertencentes a movimentos sociais e políticos. Em alguns casos, como grupos indígenas, grupos das religiões afro-brasileiras, os nativos têm seus ólogos para tratar com os pesquisadores. Assim, o antropólogo convive com outras regras que não constam nos velhos manuais científicos. Deste modo, é um conhecimento fundamentado em um poder legitimado pela academia e, ao mesmo tempo, sujeito às regras de um outro campo, o universo do pesquisado. A negociação assume formas diversas, quer se trate de bairros urbanos, quer de grupos indígenas ou outros. O grau de distanciamento e proximidade com nativos é avaliado no decorrer da experiência de campo, definindo a continuidade ou não da pesquisa. $\mathrm{O}$ campo de pesquisa condiciona a observação, uma vez que o antropólogo esbarra sempre em posições políticas e hierárquicas de "nativos" e suas relações, que têm seus códigos, seus sistemas de pensamento, suas lógicas, seu contato com o contexto mais amplo.

Seguir esta linha de discussão, é repensar o trabalho de campo, a partir da subjetividade na relação entre o antropólogo e os informantes, 
compo ponto central na construção de etnografias, conceitos e teorias na antropologia (Grossi,1992). As experiências etnográficas ocorrem através de um processo de comunicação, de trocas, de negociação entre o antropólogo e os nativos. Nestes termos, são experiências fragmentadas, com muitas vozes, que se expressam na dialogia. A realização de uma pesquisa é uma forma de comunicação entre pessoas que procuram entendimento. O empreendimento etnográfico deve voltarse para um objetivo relacional. Fatos dificilmente existem sem relações. Encontrando Taso me descobrindo é um exemplo interessante de intersubjetividade. Em oposição aos críticos positivistas, Mintz sustenta a importância da amizade para a história de Taso, seu informante, trabalhador da cana de açúcar de Porto Rico. A convivência e a afetividade permitiram chegar mais perto e mais fundo, nos significados desconhecidos entre ambos. Segundo o autor, o que tornou possível a continuidade do trabalho com Taso foi a sua convicção, de que a vida deste seu informante, e o que ela sintetiza, deveria estar disponível a outros, para que pudessem estudar e refletir sobre ela. Como escolheu Taso? Para esta indagação diz: eu não "escolhi" Taso, ele me "escolheu". Trabalhando com ele, Mintz descobriu mais sobre si mesmo (Mintz, 1980). Nessa relação o pesquisador se envolve e seus valores e sua visão de mundo passam a ser condição para compreender as diferenças.

A proposta, tanto dos pós-modernos, quanto de algumas antropólogas femininas, particularmente norte-americanas, é pensar a relação sujeito-objeto a partir das relações de gênero. James Clifford e George Marcus (1991) argumentam que o feminismo tem contribuído grandemente ao avanço da antropologia, uma vez que etnógrafas questionam, com autoridade intelectual, os cânones masculinos vigentes nas análises científicas. A aceitação da obra de Ruth Landes (1996), A cidade das mulheres, pelos autores pós-modernos, está baseada na inovação temática da obra, a experimentação formal do texto, o tipo de escrita etnográfica usado pela autora, a estratégia particular de investigação utilizada, a forma densa e multivocacional do seu estilo narrativo e a recusa em se acomodar numa explicação fixa e estável dos fenômenos. Também, o trabalho enfatiza o "eu", a experiência subjetiva da autora, expondo sobre a construção do seu objeto e a insistência em situar-se como judia e mulher (Healey, 1996). O contexto disciplinar no qual a autora 
e sua obra estavam inseridas diz respeito à escola americana de Franz Boas, o liberalismo racial sócio- científico dos EUA e os estudos afrobrasileiros das décadas de 30 e 40 . Apesar de sua ligação aos paradigmas da Antropologia norte-americana, Landes permitiu que o Brasil the falasse em seus próprios termos. A exclusão do trabalho de Landes da academia, na época, refere-se à sua inovação temática, isto é, estudar raça e gênero juntos e seu estilo narrativo, excessivamente feminino, multivocacional e literato .O olhar feminino da obra é criticado pelos antropólogos como uma auto-afirmação das mulheres norte-americanas. Além disso, esse tipo de estudo era marginalizado no meio acadêmico por estar ligado a uma história mais ampla, envolvendo questionamentos ao racismo e ao imperialismo.

Dentro de uma perspectiva relativizadora aceita-se que a antropologia foi por muito tempo etnocêntrica e, com a inserção das mulheres no campo antropológico, descobre-se também que a antropologia era androcêntrica. Relatos de mulheres em campo mostram a descoberta da identidade feminina pelo jogo de contrastes - igualdade $\mathrm{x}$ diferença - e problematizam a subjetividade na prática antropológica, a partir dos conflitos vividos em campos ligados à sexualidade (Grossi, 1992). A relação sujeito / objeto permeada pela subjetividade foi trazida pelas mulheres antropólogas. Os homens antropólogos pouco explicitam seus questionamentos subjetivos ligados ao gênero. Os questionamentos da relação sujeito/objeto, traduzidos pelos homens, remetem à destruição do "mito do antropólogo neutro" e ao questionamento da problemática do poder, isto é, a questão do colonialismo e suas consequiências aos povos colonizados. Um dos conflitos vivenciados pelas mulheres antropólogas é o "imaginário de mulher", presente nos lugares onde pesquisam e na visão dos informantes. Para se proteger desse risco, muitas antropólogas se escondem sob a capa do terceiro gênero, nem homem, nem mulher, mas um ser neutro, assexuado (Grossi, 1992).

Autores pós - modernos analisam e criticam o significado da relação pesquisador-pesquisado e, especificamente, antropólogo / informante, na Antropologia. Os "etnógrafos" clássicos, só tardiamente, relataram suas experiências em campo, num livro - diário em que expressam as ambigüidades, as angústias e o sofrimento do antropólogo de carne e osso face ao outro. Nesse sentido, Um Diário no sentido estrito do termo, de Malinowski (1997), segundo Geertz, "demole o mito do pesquisador de 
campo semicamaleão, que se adapta perfeitamente ao ambiente exótico que o rodeia, um milagre ambulante em empatia, tato paciência e cosmopolitismo" (Geertz,1998, p.85). O mergulho na "subjetividade" foi percebido até pouco tempo atrás como "indiscrição" ou "auto-exposição ridícula". Desse modo, autores em seus diários esclarecem sobre a natureza de suas experiências pessoais como relatos literários e não como antropologia (Grossi, 1992). Hoje, porém, nas introduções dos trabalhos científicos, já é possível encontrar escritos sobre o encontro etnográfico.

Em o Oficio do etnólogo ou como ter anthropological blues, $\mathrm{Da}$ Matta (1984) argumenta que a formação do pesquisador propõe o planejamento de todas as fases de seu trabalho, mas não o prepara para ver, com olhos críticos, seus humores, cansaços e infortúnios, enquanto observador participante. Também não explica o mecanismo pelo qual ele chega a descobrir novidades. O convívio com o outro, o pensar sobre si mesmo permeiam a "viagem antropológica", como um blue que se insinua e ganha força pela repetição de suas frases ,até se tornar perceptível. Sentimento e emoção serão os hóspedes não convidados da situação etnográfica que se entrelaçam com a rotina intelectualizada.

Entretanto, a subjetividade como instrumento de trabalho não deve ser justificativa para a indefinição dos limites entre ciência e ideologia. Portanto, não deve servir de desculpas para repor a oposição entre verdade a mistificação. A relação intersubjetiva não é o encontro de indivíduos autônomos e auto- suficientes. É uma comunicação simbólica que supõe a repõe processos básicos responsáveis pela criação de significados e grupos (Cardoso, 1986). Nesse encontro, as pessoas se estranham e fazem um movimento de aproximação, desvendando sentidos ocultos e explicitando relações desconhecidas.

A dimensão política do trabalho antropológico com grupos "marginalizados" é outro tema evidenciado nas pesquisas atuais. Nesses termos, exprime-se a questão do poder, não apenas sobre a interpelação do "outro", mas de ser o seu intermediário no contato com a sociedade inclusiva. É impossível ficar neutro, uma vez que a comunidade atribui um papel ao antropólogo e espera um engajamento com efeitos concretos. Neste sentido, emerge o problema de como falar sobre o grupo sem incriminá-lo e sem dar armas para os outros grupos, que preferem vê-lo dizimado (Lagrou, 1992). 
O trabalho de campo em termos da relação pesquisador / pesquisado permite reflexões à construção de etnografias e conceitos na antropologia. O entendimento das diferentes interpretações, para um mesmo objeto, além das diferentes referências sobre o pensamento social, implica em interpretações inerentes à própria relação subjetiva que marca cada trabalho. O “olhar" sobre um recorte empírico é formado pela história individual do pesquisador e conduz à percepção de vários aspectos, como responsáveis por diferentes leituras, tais como: as condições políticas e ideológicas em que se realiza o encontro etnográfico, as relações dialógicas, a questão de gênero, classe social, status e prestígio.

A convivência com os informantes - "a perspectiva intersticial" - continua sendo a forma como os antropólogos contemporâneos têm experiências com outros grupos. No encontro etnográfico, procuram sensibilizar-se ao ritual de integração em grupos com códigos particulares, fazem alianças, atam laços, "seduzem" e assumem ,em alguns casos, o papel de mediadores, a fim de compartilhar dos interesses políticos do grupo com o contexto mais amplo. O envolvimento com as rotinas diárias permite conhecer o modo de operar sistemas simbólicos diversos que são postos em movimento por discursos do pesquisador e dos pesquisados. A negociação do valor cultural nas condições de intercâmbio cultural vem sendo analisada de maneira persuasiva, assim como a exploração das possibilidades de uma etnografia mais radicalmente descentrada ou deslegitimada. Essa etnografia evitaria os tipos de autoridade interpretativa, corporificados na figura de um exegeta distante, que penetraria nos emaranhados mistérios de outra cultura, a fim de trazer à luz um sentido oculto, não somente do observador, como também dos próprios participantes dessa cultura (Clifford, 1998).

Para Geertz a compreensão etnográfica que está ligada ao processo tradutório, é tanto "achada" como "perdida" nele. A tentativa de apreender uma cultura implica "em não olhar por trás das aparências que nos vinculam com ela, mas olhar através delas" (Geertz,1998, p.70). O autor está convencido da necessidade da etnografia ajudar a ampliar a possibilidade de um discurso inteligível entre pessoas bem diferentes umas das outras, em termos de interesse, de perspectiva, de riqueza, de poder e, não obstante, contidas num mundo em que, lançadas como estão numa interminável conexão, é cada vez mais difícil fugir ao universo 
uma das outras e, no processo, permanecer com grande grau de autoconsciência, acerca de o seu próprio poder e dos seus próprios efeitos (Geertz, 1998). A força e o valor ético desse empreendimento são inseparáveis de um reconhecimento da própria posição e identidade cultural, por mais provisória e prejudicada que elas possam ser.

Crapanzano considera forçada a interpretação de Geertz da briga de galos como uma forma de arte possível de ser discutida. A briga de galos será, por certo, para os balineses, brigas de galos e não imagens, ficções, modelos e metáforas. Ao criticar a arrogação de Geertz, de autoridade interpretativa, "lamenta a compreensão elaborada do ponto de vista elaborado do nativo elaborado, supondo a possibilidade de alguma compreensão pura do nativo do ponto de vista nativo" (Crapanzano,1991, p.119). Assim, suas interpretações mostram que "a cultura de um povo é um conjunto de textos, eles mesmos conjuntos, que o antropólogo se empenha em ler por cima do ombro daqueles a quem eles propriamente pertencem" (Geertz,1978, p. 321). Apesar disso, a sua obra não deixa de dizer acerca das relações entre o complexo valor das formas culturais e as complexas formas de valoração efetuadas por e entre culturas (Crapanzano, 1991).

O paradoxo do valor intercultural, para Geertz, reside em como se envolver com as vozes, experiências e valores dos outros sem se sentir a tentação de formas de auto-imolação imunizante : é a dupla percepção de que a nossa não é senão uma voz entre muitas e que, como é a única que temos à nossa disposição, temos necessariamente de falar com ela (Geertz, 1998). É a dificuldade de mediação da questão do valor, seja do ponto de vista do eu que se completa a si mesmo no desvio do "outro", seja do $e$ u que usa o outro de modo grandioso para celebrar "a sua falta de ser" (Condor,1994, p. 259).

O estudo do "outro de dentro" tem propiciado discussões, a antropólogos, sobre as dificuldades em se transpor a realidade vivida no campo, para a elaboração do discurso científico, construindo um texto etnográfico que contemple as inúmeras possibilidades de interpretação, e as difíceis negociações entre antropólogo e seus informantes, presentes no trabalho de campo. Na passagem das experiências para o texto há perdas do vivido, já que o texto representa uma forma de adequação ou transformação da realidade que se mostra 
multifacetada'e dinâmica. $\mathrm{O}$ comum é uma redução das experiências vividas em campo, quando transpostas ao texto, delimitando-as apenas às introduções metodológicas e às notas de rodapé. Há também distinção entre o nível descritivo e o interpretativo explicativo. A descrição já é, em si mesma, uma interpretação, não sendo possível separar fato empírico da interpretação (Silva, 1998). Na passagem do campo para o texto, o rigor acadêmico impõe o distanciamento das experiências subjetivas vivenciadas em campo para que o texto não perca o seu caráter científico.

Uma rede social, mais ou menos externa no espaço e no tempo, é percorrida por uma representação. Estamos então perante uma representação tipicamente cultural, que consiste numa multiplicidade de versões mentais e públicas, ligadas entre si, simultaneamente, pela semelhança do conteúdo. O conjunto de representações, desse tipo, que circula num grupo humano, constitui a respectiva cultura (Sperber, 1992). Todas as representações mentais - mesmo as comunicadas uma só vez - são concebidas e compreendidas no contexto de um saber partilhado e constituem, em certo sentido, versões periféricas, transformações idiossincráticas de representações comuns.

Cada etnógrafo vive no terreno de uma experiência única. Certamente aproveita a experiência de seus antecessores, os ensinamentos que recebeu e os instrumentos e técnicas da profissão, mas o instrumento principal do seu trabalho é um conjunto de relações pessoais, por meio das quais se liga a uma rede cultural particular. Esta última constitui-se como um instrumento que constrói relações pessoais, devendo o outro participar, com as suas idéias e sentimentos, na respectiva construção. A transmissão deste instrumento implica em descrever, interpretar, concentrando as diversas versões de que se compõe uma representação cultural, uma versão exígua, portanto, mais inteligível para os seus leitores. "O antropólogo tem por tarefa explicar as representações culturais, isto é, descrever os fatores que determinam a seleção de certas representações e a sua partilha por um grupo social. O etnógrafo tem por tarefa, não como ponto único mas principal, tornar inteligível a experiência dos seres humanos, tal como a sua pertença a um grupo social contribui para determiná-la" ( Sperber,1992, p. 57).

O que se expressa aqui é a problemática da auto-reflexão, ou seja, o contexto do encontro etnográfico em si. Este último reveste-se 
em instâncias específicas de discursos desenvolvidas a partir de três personagens - o antropólogo, o informante, e o leitor - que formam o contexto de auto - reflexão e não um universo particular de visão de mundo (Peirano,1986). Numa antropologia dos discursos tradicionais a "cultura" era concebida como um objeto a ser descrito, num corpus estável de símbolos e significados a serem interpretados. Agora, adere-se uma definição de cultura temporal e emergente, na qual os códigos e representações são suscetíveis de serem contestados. A tarefa da etnografia passa a ser experimental. O leitor deixa de lado sua atitude passiva e é visto como implicado no projeto de construção etnográfica. 0 leitor se une ao diálogo aceitando, rejeitando ou modificando a percepção do antropólogo.

A "descrição participante" envolve também transformar as pessoas, que se conhece e se vivencia no cotidiano da experiência etnográfica, em sujeitos coletivos. Ao terem contato com esse trabalho as pessoas não se reconhecem no texto. A impessoalidade pode bem ser traduzida como neutralidade científica, mas também como negociação entre pesquisador e pesquisado para que suas identidades não sejam reveladas. Também há a necessidade de preservar o anonimato dos interlocutores, o que não impede que se reflita no texto os motivos e as conseqüências destes procedimentos.

0 cuidado na elaboração das representações etnográficas supõe a facilidade ou não de acesso do grupo pesquisado às etnografias. A dificuldade de acesso aos interlocutores aumenta a liberdade do autor do texto na exposição de certas informações. Entretanto, a dialogia nas etnografias de campo precisa ser transposta para o texto. É preciso expor os conteúdos das etnografias para a academia e para o grupo co-autor. Isso impõe refletir sobre as condições políticas que têm sido realizadas com informantes e os diálogos na academia.

Algumas pesquisas tratam do prestígio da linguagem científica desfrutada no meio de grupos, como os das religiões afro-brasileiras. Os textos etnográficos, construídos numa determinada situação de campo, acabam voltando aos nativos, fornecendo enunciados que os etnógrafos deveriam considerar na construção de suas representações sobre o grupo. Se $o$ antropólogo produz interpretações de primeira ou segunda mão, por sobre os ombros dos nativos, não se pode deixar de 
levar em conta o fato de que os nativos também poderão ler a sua cultura por sobre os ombros dos antropólogos (Silva, 1998). Nos estudos de religiões afro-brasileiras manifesta-se a dependência mútua antropólogo/terreiro. Estar perto das "evidências consolidadas" é uma estratégia de legitimação do seu trabalho e da qualidade de sua etnografia. O conhecimento das etnografias demonstra a legitimação e influências dos sacerdotes. Há também a produção de textos elaborados por integrantes da religião, influenciada pelo modelo da escrita etnográfica. $\mathrm{O}$ estudo etnográfico não corresponde à forma como o conhecimento é transmitido nos terreiros, porém escrever é um desafio para uma religião em que a transmissão é feita por tradição oral. A literatura construída pelos sacerdotes, ao aproximar-se do modelo acadêmico, evidencia a influência das etnografias no mundo dos terreiros. Essas etnografias, construídas como "modelos da realidade", são utilizadas pelos religiosos como "modelos para a realidade", fornecendo um padrão, através do qual os religiosos representam o universo religioso, na prática, através de seus livros (Silva, 1998). Muitos antropólogos vêm submetendo suas informações, os resultados parciais ou finais do seu trabalho à apreciação dos seus informantes, seja para autorizar informações, seja para sugerir interpretações. $\mathrm{O}$ que se pretende é perceber até que ponto a lógica das interpretações é confirmada ou não pelos grupos, bem como quais os significados que se pode inferir de cada uma das posições.

Mais do que isso, não podemos esquecer que, além da observação participante, cada vez mais o antropólogo utiliza-se de recursos como gravadores, filmadoras, máquinas fotográficas. Esses recursos permitem um registro com maior detalhamento, mas isto não significa que estamos mais próximos do real, do que na época em que os cadernos de campo eram um dos instrumentos privilegiados. Filmar e fotografar impõem uma relação de intimidade e de desconfiança com o grupo. E o que ouvir e o que registrar depende da representação que os grupos fazem destas técnicas.

A fotografia, o cinema, a televisão, a publicidade, o computador são hoje elementos presentes no nosso cotidiano de modo cada vez mais íntimo. Agimos e interpretamos com as imagens, sem percebermos o quanto elas impregnam valores fundamentais de nossa cultura. As imagens não falam por si só, mas expressam e dialogam com modos de vida típicos das sociedades que as produzem. Nesse diálogo elas se 
referem às questões culturais e políticas, exprimindo a diversidade de grupos e de ideologias, em determinados momentos históricos. Imagens, assim como textos, são artefatos culturais. A produção e a análise destes registros permitem a reconstituição da história cultural de grupos sociais, bem como uma melhor compreensão de processos de mudança social, do impacto das frentes econômicas e da dinâmica das relações interétnicas. A imagem, pela especificidade de sua linguagem, é mais flexível do que o texto, em sua estrutura narrativa, no sentido de acomodar múltiplos significados. É um elemento essencial para que se possa analisar como estes significados são construídos, incutidos e veiculados pelo meio social. Também, o modo como as imagens são recebidas pelo receptor implica em uma negociação de sentido que transcende a própria imagem que se realiza no contexto da cultura e dos textos culturais com que ela convive. A imagem aponta para estes textos, podendo ser lida., ela própria, como um texto (Novaes, 1998). Nesse sentido, a idéia de multimídia aparece tornando possíveis diversos padrões de interatividade. Imagens e sons podem, de acordo com interesses em cada pesquisa, ser mais ou menos importantes. Incorporar meios de produção de imagem animada à investigação científica impõe uma reflexão a respeito dos seus alcances e limites (Goifman, 1998).

A utilização de outros registros, na pesquisa etnográfica, não pode mais ser restrita aos cadernos de campo e aos gravadores, emergindo uma "metodologia interativa" com técnicas múltiplas .Os novos suportes da hipermídia (imagens em movimento, hipertexto) apresentam caminhos potencialmente infindáveis para a construção das etnografias, principalmente, porque postulam a possibilidade de: uma reconfiguração da natureza do trabalho de campo feito com e pela hipermídia; a reconfiguração da relação descrição - interpretação postulada pelo texto etnográfico clássico e revista pelo hipertexto etnográfico pós moderno, com conseqüências evidentes para o principal objeto teórico da antropologia - os significados da cultura (Silva, 1998).

Avaliar o retorno que as representações antropológicas têm junto aos grupos estudados, permite, em grande medida, avaliar o papel de influência e poder que os resultados da antropologia podem ter junto às práticas sociais, como os movimentos políticos organizados das chamadas minorias. 
Quando se coloca, lado a lado, representantes dos grupos estudados e antropólogos, para refletir sobre a relação sujeito a objeto e a produção do conhecimento, está-se enfrentando os problemas que a pós - modernidade da antropologia vem enfrentando. Neste sentido, não se fazem mais objetos como antigamente, pois são todos, além de objetos, pesquisadores sujeitos e enquanto tais criam seus grupos especializados em responder, de um lado, o que o antropólogo quer ouvir e, de outro, estão dispostos a cobrar dos pesquisadores (Montes, 1994). Objetos pesquisados reivindicam para si, e com direito, a condição de produzir o seu próprio discurso e saber o seu lugar na sociedade da qual todos fazemos parte. Enquanto objetos sujeitos denunciam sobre o conhecimento produzido na academia que, nas suas concepções, tem servido para ser usado contra eles. Nesse sentido, a maior parte do que se produz é transformado em instrumento de controle, manipulação e dominação, porque vivemos numa sociedade violenta, desigual e de classes e de identidades reflexivas, manifestando-se a disputa e o poder. A antropologia é uma disciplina da reflexividade que se impõe entre o "eu e o outro". Pela mediação do espelho é capaz de estabelecer um lugar de onde é possível compreender a ambos como iguais. Deste modo, a produção do conhecimento deve ser percebida como "horizonte à frente e não apenas como horizonte de poder". O conhecimento, visto além do poder, permite fazer pontes e construir uma dimensão da relação entre pesquisador e seu universo de pesquisa. A dimensão da reciprocidade permite perceber aquilo que faz a humanidade, isto é , a capacidade de troca (Montes, 1994).

O que também emerge é a responsabilidade do pesquisador em falar ou não sobre os "segredos" do grupo estudado. Os estudos antropológicos sobre religiões afro-brasileiras vêm tratando do "segredo", daquilo que não se penetra sem a iniciação e sem um longo período de intimidade e de confiança mútua com o grupo estudado. Apesar de que as relações não sejam hoje tão fechadas, como há tempos atrás, a força do "segredo" existe tanto para as pessoas de fora estudiosos - quanto para os próprios membros dos grupos.

Assim como Silva (1998), Carvalho (1994) chama a atenção para a parte mais essencial de uma ética antropológica: a construção de textos que deverá ser passada pelo consenso dos membros ou, pelo menos, 
pelơ consentimento da maioria da coletividade. $O$ cuidado ao entrar em um mundo alternativo, de formas simbólicas, deve ser o de preservá-lo e contribuir para sua continuidade. Se o antropólogo tem a sensibilidade de descobrir algo maravilhoso, deve reunir mais sensibilidade para não provocar a sua desintegração e desencantamento. Ao deparar-se com o belo, com o fascinante, acaba sendo tocado pela parte mais destrutiva de seu sistema de valores: o desejo de possuir o que é do grupo estudado. Mais ainda, diferente da distância humana no período colonialista, no qual a produção de obras era para um circulo acadêmico, hoje interessa recuperar o elo entre os dois mundos e buscar um consenso, entre o interesse acadêmico e do grupo estudado, no momento em que devemos escrever ou nos calar (Carvalho, 1994). Nesses termos, do ponto de vista da produção do conhecimento e da política é preciso pensar na idéia de humanidade e de igualdade dos seres humanos, para a preservação de heranças culturais, revelando a formação da cultura brasileira.

A interação contínua num mundo globalizado se expressa na resistência e na acomodação de grupos sociais, revelando as semelhanças e diferenças entre o global e o local e a tendência para a participação autocontrolada na integração global. Para tal, Marcus propõe a redefinição do observador e do observado, criticando a "etnografia" realista e propondo uma abordagem modernista, a fim de refletir sobre os dilemas da "etnografia" na modernidade. A primeira define um contexto social específico para a identidade, baseando-se no local de moradia. Em oposição, a segunda reconhece identidades múltiplas e dispersas, em muitos lugares. Outra problematização é a noção de tempo, uma discussão que apresenta o entendimento da memória nos seus múltiplos sinais e expressões com auto-reconhecimento da identidade, para compreender os processos de diversidade que se derivam da sua emergência no meio de diversas associações, processando-se na memória coletiva e individual . A memória é fragmentada. E é sobre os fragmentos, os quais se reagrupam, se reordenam em suas conexões e se reconhecem, que é possível ligar o espaço localizado ao curso da história (Marcus, 1991). Nesta linha de discussão do mundo contemporâneo é, também, Augé que traz a sua reflexão. Entre as várias questões que levanta, discute categorias tais como: "lugar", considerando o espaço identitário das relações pessoais; "não-lugar", considerando $o$ espaço não-identitário, da circulação 
acelerada das pessoas em locais de passagem como: metrô, supermercados, aeroportos, vias expressas, trevos rodoviários, cadeias de hotéis. Argumenta que, para compreender o que denomina de mundo da supermodernidade, "temos que reaprender a pensar o espaço" (Augé, 1994, p. 38).

A crise do pensamento antropológico coincide com o seu sucesso para além dos muros da academia. A importância da cultura é difundida por vários setores da sociedade e a antropologia é convocada a emitir pareceres sobre os problemas sociais. 0 que tem a antropologia a dizer da crise do desenvolvimento econômico e da humanidade, da descrença nas promessas de um mundo melhor pautado no progresso tecnológico, a fragilidade da democracia liberal que engendra novas formas de opressão e colapso do Estado? O "relativismo cultural" nesse sentido deve ser um instrumento para compreender as sociedades complexas, pois os processos de globalização têm proposto e renovado as diferenças entre cultura a nações. A cultura tornou-se um problema para a consciência contemporânea e a análise de seu cotidiano e suas mediações simbólicas, um caminho para a compreensão de certos problemas sociais. Faz-se urgente uma teoria capaz de perceber o modo como a variedade de experiências produz representações sociais e como o pensamento social e político hegemônico se enraízam no cotidiano (Monteiro,1991). É preciso aliar as interpretações intersticiais às questões econômicas e políticas mais amplas.

O fazer antropológico na contemporaneidade envolve a compreensão do "outro", da própria cultura e conduz certamente a pensar sobre a nossa relação com ele e sobre o seu lugar em nosso contexto social. Os grupos minoritários têm-se constituído como bom exemplo para entender como a antropologia vem repensando o seu papel político e social.

\section{Momento de juntar pistas...}

Diferente da interpretação da antropologia moderna, a etnografia pós- moderna pretende estabelecer uma negociação, um diálogo com os grupos estudados, sugerindo a expressão de trocas entre uma multiplicidade de vozes. Escrever etnografia, assim, é ter como modelo o diálogo, a polifonia. A idéia é diluir no texto a presença do autor, revelando-a como "autoria dispersa", representando muitas vozes, muitas 
perspectivas, a produção de textos com plurivocalidade - citações de depoimentos, autoria coletiva, dar voz ao grupo estudado. Nas etnografias é possível representar um novo conceito de cultura, pois a produção textual situa as interpretações culturais em diferentes conteúdos intercambiáveis e obriga os escritores a encontrar diversas maneiras de apresentar realidades que são negociadas como intersubjetivas. Cultura é, assim, algo sempre relacional, uma inscrição dos processos comunicacionais que existem historicamente entre sujeitos em relação de poder. Dialogismo e polifonia são reconhecidos como modos de produção textual, a autoridade monofônica é questionada. 0 antropólogo não se encontra mais numa situação privilegiada em relação à produção do conhecimento. Sobre a autoridade etnográfica ele está numa situação justaposta. O leitor, por sua vez, é participante ativo na construção do sentido do texto.

Iluminando reflexões a respeito da dimensão política e da critica cultural, Rabinow considera que a perspectiva política é presença marcante nos textos pós-modernos, porém em sua maioria, as questões políticas são sugeridas (críticas ao colonialismo).O que se expressa é a política textual dos estilos e opções textuais. Nesse sentido, a sua crítica é de que a discussão textual nunca vai se sustentar por si só, - ela deveria estar aliada a uma análise que tentasse localizar autores em instituições, textos e instituições num campo epistemológico e de poder, com estratégias próprias e marcados historicamente. Deveria, ainda, analisar as relações de poder, que definem enunciados aceitos como verdadeiros, em cada momento. Mais ainda, deveria incorporar uma análise sociológica, estabelecendo as mediações entre as críticas, o colonialismo e os experimentos textuais. Deste modo, chama a atenção para o questionamento da academia americana e seus jogos de poder (Rabinow, 1991).

Além das reflexões quanto às condições de produção de conhecimento, o que se vislumbra é a realização da crítica cultural. Enquanto a antropologia realizada nas metrópoles se vê malograda quanto ao projeto de crítica cultural, as antropologias nativas, tendo um "outro" que faz parte da própria cultura do investigador, são inevitavelmente conduzidas a pensar criticamente sobre a relação com ele e o seu lugar na sociedade. 
As referências pós - modernas e as próprias especificidades do "outro" na sociedade brasileira têm proporcionado reflexões significativas a respeito do trabalho de campo na relação pesquisador/ pesquisado, da passagem experiência / texto, do poder científico e não científico, da troca, dentre outras questões.

Ao nos depararmos com a crítica pós-moderma, por um lado, é importante voltar a atenção às observações de Peirano, quando, ao se declarar a "favor da etnografia", faz provocações, argumentando que toda etnografia precisa ser rica, para que possa sustentar uma reanálise dos dados iniciais, sendo que a reanálise de um corpo etnográfico é a prova da adequação e qualidade da etnografia (Peirano,1991). Por outro lado, em que pesem as críticas aos pós - modernos, é preciso perceber que, esses debates contemporâneos, têm possibilitado um constante repensar sobre metodologias e teorias que fundamentam o conhecimento antropológico, revelando que não existe uma fórmula única na formação acadêmica, mas que estamos envolvidos em contínuas polêmicas, bem como acompanhando instituições, a produção de conhecimentos, o envolvimento com a sociedade mais ampla. Trata-se de percebermos a dinâmica cultural nos processos de globalização e o modo como a antropologia vem enfrentando a problemática da contemporaneidade. Nesses termos, há a necessidade de se aliarem os interesses da academia aos interesses dos grupos estudados. Não podemos negar o outro que está constantemente presente na construção da "leitura" que fazemos de suas práticas sociais. Que "barulho" saudável é este dos pós-modernos.

\section{Referências Bibliográficas}

AUGË, Marc. Os não lugares. Introdução a uma antropologia da supermodernidade. São Paulo: Papiros. 1994.

BOURDIEU, Pierre. O campo científico. In : ORTIZ, Renato (org.). Coleção Grandes Cientistas Sociais -39. São Paulo : Ática. 1983.

BUFFON, Roseli. Encontrando uma tribo masculina de camadas médias. In: GROSSI, Miriam (org.). Trabalho de campo e subjetividade. Florianópolis: UFSC .1992. 
CALDEIRA, Tereza P. A presença do autor e a pós-modernidade. Novos Estudos Cebrap. São Paulo: n. 21, 1988.

CRAPANZANO, Vicent. El dilema de 1 Hermes: la mascara de Ia subversión en las descripciones etnográficas. In: CLIFFORD, James \& MARCUS, George. Retóricas de la Antropologia. Madri: Júcar. 1991.

sity of Chicago Press, 1990.

Tuhami: Portrait of a Moroccan.Chicago: The Univer-

CARDOSO, Ruth C. L. A aventura de antropólogos em campo ou como esperar escapar das armadilhas do método. In: CARDOSO, Ruth C. L. A aventura antropológica: teoria e pesquisa. Rio de Janeiro : Paz a Terra. 1986.

CARVALHO, José Jorge de. A racionalidade antropológica em face o segredo. Anuário antropológico/84. Rio do Janeiro: Tempo Brasileiro. 1985

CLIFFORD, James \& MARCUS, George. Verdades parciales. Retóricas de la Antropologia. Madri: Júcar. 1991.

CLIFFORD, James. A experiência etnográfica: antropologia e literatura no Séc. XX . Rio de Janeiro: Editora UFRJ. 1998.

CONNOR, Steven. Teoria e valor cultural. São Paulo: Loyola. 1994.

DAMATTA, Roberto. Relativizando: uma introdução à Antropologia social. Rio de Janeiro: Zahar. 1984

GEERTZ, Clifford. Do ponto de vista dos nativos: a natureza do entendimento antropológico. O saber local. Petrópolis: Vozes. 1998.

El antropologo como autor. Barcelona: Paidós. 1989.

A Interpretação das culturas. Rio de Janeiro: Zahar. 1978.

GOIFMAN, Kiko. Valetes en slow motion - a morte do tempo na prisão: imagens e textos. Campinas: Editora Unicamp. 1998.

GROSSI, Miriam. Na busca do outro encontra-se a si mesmo. In: GROSSI, Miriam (org.). Trabalho de campo e subjetividade. Florianópolis: UFSC. 1992.

HEALEY, Mark. Os desencontros da tradição em cidades das mulheres: raça e gênero na etnografia de Ruth Landes. Cadernos Pagu. Campinas: Núcleo de Estudos do Gênero. Unicamp. (6-7). 1996.

LAGROU, Elsje Maria. Hermenêutica a etnografia. Revista de antropologia. São Paulo: FFLCH / USP. v.37. 1994. 
. Uma experiência visceral. In: GROSSI- Miriam (org.).

Trabalho de campo e subjetividade. Florianópolis: UFSC. 1992.

M ALINOWSKI, Bronislaw. Os argonautas do Pacífico Ocidental. In: Os Pensadores. São Paulo: Abril Cultural. 1978.

Janeiro: Record. 1997

Um diário no sentido estrito do termo. Rio de

MARCUS, George \& FISCHER, Michel J. A crisis of representation in the Human Sciences. In: Anthropology as cultural critique. Chicago: University Press. 1986.

MARCUS, George. Identidades passadas, presentes a emergentes: requisitos para etnografias sobre a modernidade no final do Séc. XX ao nível mundial. Revista de Antropologia. São Paulo: FFLCH/USP. V.34. 1991.

MINTZ, Sidney. Encontrando Taso, me descobrindo. Dados. Revista de Ciências Sociais. Rio de Janeiro: v.27.n. I . 1984.

MONTERO, Paula. Reflexões sobre uma antropologia das sociedades complexas. Revista de Antropologia. São Paulo: FFLCH/ USP. V.34. 1992.

MONTES, Maria Lúcia. Etnografia: Identidades reflexivas. In: SILVA, Vagner G. et alli (org.). Antropologia e seus espelhos. São Paulo: FFLCH / USP. 1994.

NOVAES, Sylvia Caiuby. O uso da imagem na antropologia. ln: SAMAIN, Etienne. O fotógrafo. São Paulo: Hucitec / CNPq. 1998

OLIVEIRA, Roberto Cardoso. O saber, a ética e a ação social. Manuscrito. Revista internacional de filosofia. São Paulo: FAPESP.v.Xlll . 2.1990.pp.7-22.

PEIRANO, Marina. A favor da Etnografia. Rio de Janeiro: Relume-Dumará. 1995.

O encontro etnográfico e o diálogo. Anuário antropológico/85.

Rio de Janeiro: Tempo Brasileiro. 1986́.

RABINOW, Paul. Las representaciones son hechos sociales: modernidad y post modernidad en la antropologia. Retóricas de la Antropologia . Madrid: Júcar. 1991

SILVA, Vagner G. O antropólogo a sua magia. Trabalho de campo e texto etnográfico nas pesquisas antropológicas sobre religiões afro-brasileiras. São Paulo. FFCH / USP. Tese de Doutoramento. 1998 (mimeo).

SILVA, Vagner G. et alli (org._). Abertura. In: Antropologia e seus espelhos. São Paulo: FFLCH / USP. 1994. 
SPERBER, Dan. O saber dos antropólogos. Lisboa: Edições 70. 1992.

STOCKING, George. Observers Observed. The University of Wisconsin: Press. 1983.

TRAJANO FILHO, Wilson. Oue barulho é esse o dos pós - modernos ? Anuário antropológico/86. Brasília: UNB. 1998

\section{Resumo}

$\mathrm{Na}$ construção deste ensaio, a tentativa é mostrar as questões trazidas pela pósmodernidade americana, contextualizando a produção do conhecimento antropológico clássico, discutindo metodologias características, como o trabalho de campo, a relação observador - observado, a natureza das representações etnográficas e evidenciando a relevância destas nos processos de comunicação do mundo contemporâneo.

Palavras-chave: produção do conhecimento antropológico; pós-modernidade americana; antropologia e contemporaneidade; trabalho de campo; representações etnográficas.

\section{Abstract}

Our attempt in writing this essay is to present the issues American post-modernity has brougth about, contextualizing the production of the classical anthropological knowledge,discussing typical methodologies, such as the field work, the relationship observer-observed and the nature of ethnographical representations, and evidencing their relevance in the process of communication of the contemporay world.

Key-words: production of antropological knowledge; American post-modernity; anthropology and contemporaneity; field work, ethnographical representations.

Deise Maia

é professora de Antropologia do Departamento de Ciências Sociais da UEL 